Proceedings

\title{
Ultrasound Assisted Green One Pot Synthesis of Bound Type bis-Heterocyclic furan-2-yl imidazo [1,2-a] Pyridines via GBBR +
}

\author{
Mahanandaiah Kurva and Rocío Gámez-Montaño * \\ Departamento de Química, Universidad de Guanajuato, Noria Alta S/N, Col. Noria Alta, C.P. 36050 \\ Guanajuato, Gto., Mexico; kmahanandaiah@gmail.com \\ Correspondence: rociogm@ugto.mx; +52-473-73-20006 (ext. 8191) \\ + Presented at the 22nd International Electronic Conference on Synthetic Organic Chemistry, \\ 15 November-15 December 2018; Available Online: https://sciforum.net/conference/ecsoc-22.
}

Published: 14 November 2018

\begin{abstract}
A series of six new 3-imidazo[1,2-a] pyridine furan bound type tris-heterocycles were synthesized by Ultrasound Irradiation (USI) assisted Groebke-Blackburn-Bienaymé reaction (GBBR), by employing ammonium chloride (10 mol\%) as a catalyst in excellent yields (80-93\%) under green conditions. This efficient and mild protocol has silent features such as green inexpensive and easily available catalyst and solvent at room temperature.
\end{abstract}

Keywords: Ultrasound-GBBR; tris-heterocycles; green catalyst; green one pot process

\section{Introduction}

Multicomponent reactions (MCR's) have been considered as a powerful tool for the construction of novel and complex molecular structures from simple materials due to their advantages over conventional multistep synthesis. The major advantages of MCR's over multistep synthesis include cheap and readily available reagents, convergent or high atom economy; they exhibit a very high bond-forming-index (BFI) [1-3]. The Groebke-Blackburn-Bienaymé reaction (GBBR) in the synthesis of fused heterocycles imidazo[1-4] pyridines is an important synthetic strategy as these scaffolds are found to form a very important core in numerous synthetic, pharmaceuticals and a wide variety of biologically active compounds [4]. Imidazo [1.2-a] pyridine scaffolds are present in many commercially available drugs including, alpidem (anxiolytic), minodronic acid (to treat anxiety, heart failure and osteoporosis), olprinone (cardiotonic agent), optically active GSK 812397 candidate (HIV infection), saripidem (sedative and anxiolytic), zolimidine (an antiulcer drug) and zolpidem (a hypnotic drug) are derived from imidazo[1,2-a] pyridine core entities [5-8]. Besides Imidazo[1,2-a], pyridine moieties have applications in the field of optics such as organic light-emitting devices (OLED's), fluorescent labeling, fluorescent dyes, because of their luminescent properties [9-11]. Recently furan bound to Imidazo[1,2-a] pyridine has been reported as a chemo-sensor for $\mathrm{Cu}^{2+}[12]$.

The most important approaches are: (i) Condensation of 2-aminopyridine with $\alpha$-halocarbonyl compounds [13,14], (ii) one pot condensations of aldehydes, isonitriles and 2-aminopyridines, which are well known as Groebke-Blackburn-Bienayme reaction (GBBR) [15-17], (iii) copper-catalyzed three component reactions of 2-aminopyridines, aldehydes and alkynes [18-20]. Other methods have also been developed within the last three decades [21]. Fused bicyclic imidazo[1,2-a] pyridines via GBBR methodologies using various green catalysts, such as Lewis acids, Bronsted acids, solid supported, organic bases and inorganic salts have been reported. However, these methods have limitations in terms of the use of expensive and excess amounts of catalysts, long reaction times, high temperatures, less yields and non-readily available catalysts [22,23]. Hence, in modern synthetic 
chemistry there is a necessity of development of a simple, high yielding and ecofriendly protocols for the one pot synthesis of molecules with potential applications in optic fields like fused bicyclic imidazo[1,2-a] pyridine scaffolds.

As a part of our research program to develop eco-friendly and green methodologies based on IMCRs, we recently reported the efficient ultrasound assisted synthesis of imidazopyridine analogues via GBBR [24-26].

Herein, we report a ultrasonic irradiation (USI) assisted, mild and greener GBB protocol to synthesize bound type tris-heterocycles containing furane, imidazole and pyridine aromatic heterocycles from 2-amino-pyridines, substituted furan carbaldehyde, and isocyanides using $\mathrm{NH}_{4} \mathrm{Cl}$ as a green catalyst and EtOH as a green solvent (Scheme 1).<smiles>[R][R]1ccoc1C=O</smiles><smiles>[R]Nc1c(-c2c[R]3ccn2c3)nc2ccccn12</smiles>

$\mathrm{R}_{1}=\mathrm{H}, \mathrm{Me} ; \mathrm{R}_{2}=\mathrm{Cy}, 4-\mathrm{OMe} ; \mathrm{R}_{3}=\mathrm{H}, 5-\mathrm{Cl}, 4-\mathrm{COOMe}, 4-\mathrm{CN}$

Scheme 1. Strategy for the synthesis of furan-2-yl imidazo [1,2-a] pyridines.

\section{Results and Discussion}

To develop green conditions for GBBR, we started the synthesis of furan-2yl-imidazo[1,2-a] pyridine-3-amine analogue $4 a$ by reacting 9-octyl-9H-carbazole-3-aldehyde 1 a $(1 \mathrm{mmol})$, 2aminopyridine $\mathbf{2 a}(1 \mathrm{mmol})$, cyclohexyl isonitrile $3 \mathbf{a}(1 \mathrm{mmol})$ in $\mathrm{EtOH}$ as a solvent and green catalyst such as $p$-toluene sulfonic acid (PTSA), L-proline and ammonium chloride under USI conditions (Table 1). Initially, we performed the GGBR at room temperature, however, without a catalyst no reaction was observed. (Table 1, entry 1). Additionally, on heating, the product $4 \mathbf{a}$ was obtained in $30 \%$ yield (Table 1, entry 2). Then we switched to the solvent system and considered $\mathrm{EtOH}$ as a green solvent and performed the reaction. At room temperature, in the absence of catalyst the product $4 \mathbf{a}$ was observed in traces (Table 1, entry 3). On heating at $60{ }^{\circ} \mathrm{C}$ without catalyst gave $40 \%$ of product 4a (Table 1, entry 4). Then we switched to another green catalyst PTSA at room temperature and heating conditions, which gave product $4 \mathbf{a}$ in $68 \%$ and $75 \%$ yield respectively (Table 1, entry 4 and 5). Then we switched to another catalytic system, where L-proline was the catalyst and carried out the reaction at room temperature and heating conditions and isolated product $4 \mathrm{a}$ in 46 and $56 \%$ yield respectively (Table 1, entry 6 and 7). Then we tried $\mathrm{NH}_{4} \mathrm{Cl}$ as the catalyst and carried out the reaction at different conditions at room temperature. The product $4 \mathbf{a}$ was isolated in $83 \%$ yield (Table 1, entry 8) while at at $60^{\circ} \mathrm{C}$ the product yield of 4 a increased tremendously to $93 \%$ (Table 1, entry 9). Screening various catalysts in this reaction revealed that $\mathrm{NH}_{4} \mathrm{Cl}$ was the most efficient catalyst for good conversion and was utilized for the synthesis of different analogues of imidazopyridines (4a-h). 
Table 1. Screening conditions.

\begin{tabular}{c|cccc}
\hline \\
\hline
\end{tabular}

\section{Experimental Section}

General Information: ${ }^{1} \mathrm{H}$ and ${ }^{13} \mathrm{C}$ NMR spectra were acquired on a $500 \mathrm{MHz}$ spectrometer. The solvent for the NMR samples was $\mathrm{CDCl}_{3}$. Chemical shifts were reported in parts per million ( $\left.\delta / \mathrm{ppm}\right)$. The internal reference for the NMR spectra was tetramethylsilane at $0.00 \mathrm{ppm}$. Coupling constants were reported in hertz $(\mathrm{J} / \mathrm{Hz})$. Multiplicities of the signals were reported using standard abbreviations: Singlet (s), doublet (d), triplet (t), quartet (q), and multiplet (m). IR spectra were recorded by the attenuated total reflection (ATR) method, using neat compounds. The wavelengths were reported in reciprocal centimeters $\left(v_{\max } / \mathrm{cm}^{-1}\right)$. High-resolution mass spectrometry (HRMS) spectra were acquired via electrospray ionization ESI $(+)$ and recorded via the time-of-flight (TOF) method. Reactions at reflux were performed in round-bottomed flasks, using a recirculation system mounted on a sand bath, with an electronic temperature control. Ultrasound irradiated reactions were performed in sealed vials $(10 \mathrm{~mL})$ placed into a water bath of a Branson 1510 sonicator cleaner working at $42 \mathrm{kHz}$ $\pm 6 \%$ frequencies. The reaction progress was monitored by TLC, and the spots were visualized under UV light (254 or $365 \mathrm{~nm}$ ). Flash column chromatography was performed using silica gel (230-400 mesh) and mixtures in different proportions of hexanes, with ethyl acetate as the mobile phase. Melting points were determined on a Fisher-Johns apparatus and were uncorrected.

General method: In a vial (10 mL) containing a solution of furan carbaldehyde (1.0 equiv.), EtOH [0.5 $\mathrm{M}]$ was added sequentially to 2-aminopyridine (1.0 equiv.), ammonium chloride ( 0.1 equiv.) and the corresponding isocyanide (1.0 equiv.). The vial was closed, and the reaction mixture was sonicated $(42 \mathrm{kHz} \pm 6 \%)$ at room temperature for $3 \mathrm{~h}$. The solid products obtained from the reaction were filtered and washed with deionized water $(10 \mathrm{~mL})$ and used as such for analytical characterization.

Spectral data

N-cyclohexyl-2-(furan-2-yl)imidazo[1,2-a]pyridin-3-amine. ${ }^{1} \mathrm{H}$ NMR $\left(500 \mathrm{MHz}, \mathrm{CDCl}_{3}\right) \delta 7.97$ (dd, J $=6.9,0.8 \mathrm{~Hz}, 1 \mathrm{H}), 7.41(\mathrm{dd}, J=6.5,0.7 \mathrm{~Hz}, 2 \mathrm{H}), 7.02(\mathrm{dd}, J=8.4,7.3 \mathrm{~Hz}, 1 \mathrm{H}), 3.53(\mathrm{~s}, 1 \mathrm{H}), 2.91-2.85(\mathrm{~m}$, 1H), 1.83-1.79 (m, 2H), 1.67-1.63 (m, 2H), 1.54-1.50 (m, 1H), 1.23-1.10 (m, 5H) ppm. ${ }^{13} \mathrm{C}$ NMR (126 $\left.\mathrm{MHz}, \mathrm{CDCl}_{3}\right) \delta 150.4,141.8,141.3,128.1,125.5,123.8,122.7,117.2,111.5,111.4,106.3,57.0,34.1,25.7$, $24.9 \mathrm{ppm}$. HRMS (ESI-TOF) $\mathrm{m} / z$ [M + H] $]^{+}$Calcd for $\mathrm{C}_{17} \mathrm{H}_{19} \mathrm{~N}_{3} \mathrm{O} 282.1601$, found 282.1619. 


\section{Conclusions}

We have developed the first efficient and mild USI assisted GBB based methodology for the green synthesis of new tris-heterocyclic furan-2yl-imidazo[1,2-a] pyridine-3-amines in excellent overall yields. To the best of our knowledge, this is the first ultrasound assisted GBBR using green, readily available, inexpensive catalyst in mild conditions. Compared to the previously reported green expensive or non-readily available catalyzed GBBRs, herein we are the first to report the efficient catalytic use of inexpensive $\mathrm{NH}_{4} \mathrm{Cl}$ as a green catalyst in GBBR using furfural as a component.

Acknowledgments: R.G.M. thanks CONACYT for financial support (DAIP-UG (193/2017) and CONACYT (CB2016-285622) projects. M.K (632715/338546) thanks CONACYT-México for the scholarship and Laboratorio Nacional de Caracterización de Propiedades Fisicoquímícas y Estructura Molecular (CONACYT-México, Project: 123732).

Conflicts of Interest: The authors declare no conflicts of interest.

\section{References}

1. Goutam, B.; Suvankar, D.; Bismuth nitrate-catalyzed multicomponent reaction for efficient and one-pot synthesis of densely functionalized piperidine scaffolds at room temperature. Tetrahedron Lett. 2012, 53, 1479-1484, doi:10.1016/j.tetlet.2012.01.042.

2. Chennan, R.; Young, W.K. Tetrachlorosilane catalyzed multicomponent one-step fusion of bio-pertinent pyrimidine heterocycles. Tetrahedron 2008, 64, 5023-5031, doi:10.1016/j.tet.2008.03.078.

3. Domiling, A.; Wei, W.; Kan, W. Chemistry and Biology of Multicomponent Reactions. Chem. Rev. 2012, 112, 3083-3135, doi:10.1021/cr100233r.

4. Christopher, H.; Yeon, S.L. Emerging approaches for the syntheses of bicyclic imidazo[1,2-x]-heterocycles. Mol. Divers. 2008, 12, 1-15, doi:10.1007/s11030-008-9072-1.

5. Byth, K.F.; Culshaw, J.D.; Green, S.; Oakes, S.E.; Thomas, A.P. Imidazo[1,2-a]pyridines. Part 2: SAR and optimisation of a potent and selective class of cyclin-dependent kinase inhibitors. Bioorg. Med. Chem. Lett. 2004, 14, 2245-2248, doi:10.1016/j.bmcl.2004.02.015.

6. Kishino, H.; Moriya, M.; Sakuraba, S.; Sakamoto, T.; Takahashi, H.; Suzuki, T.; Moriya, R.; Ito, M.; Iwaasa, H.; Takenaga, N.; et al. Discovery of imidazo[1,2-a]pyridines as potent MCH1R antagonists. Bioorg. Med. Chem. Lett. 2009, 19, 4589-4593, doi:10.1016/j.bmcl.2009.06.101.

7. Warshakoon, N.C.; Wu, S.; Boyer, A.; Kawamoto, R.; Sheville, J.; Renock, S.; Xu, K.; Pokross, M.; Evdokimov, A.G.; Walter, R.; et al. A novel series of imidazo[1,2- $a$ ] pyridine derivatives as HIF-1 $\alpha$ prolyl hydroxylase inhibitors. Bioorg. Med. Chem. Lett. 2006, 16, 5598-5601, doi:10.1016/j.bmcl.2006.08.089.

8. Zhuang, Z.-P.; Kung, M.-P.; Wilson, A.; Lee, C.-W.; Plössl, K.; Hou, C.; Holtzman, D.M.; Kung, H.F. Structure-Activity Relationship of Imidazo[1,2-a]pyridines as Ligands for Detecting $\beta$-Amyloid Plaques in the Brain. J. Med. Chem. 2003, 46, 237-243, doi:10.1021/jm020351j.

9. Firmansyah, D.; Ciuciu, A.I.; Hugues, V.; Blanchard-Desce, M.; Flamigni, L.; Gryko, D.T. Bright, Fluorescent Dyes Based on Imidazo[1,2-a] pyridines that are Capable of Two-Photon Absorption. Chem. Asian J. 2013, 8, 1279-1294, doi:10.1002/asia.201300058.

10. Nagarajan, N.; Velmurugan, G.; Prakash, A.; Shakti, N.; Katiyar, M.; Venuvanalingam, P.; Renganathan, R. Highly Emissive Luminogens Based on Imidazo[1,2-a]pyridine for Electroluminescent Applications. Chem. Asian J. 2014, 9, 294-304, doi:10.1002/asia.201301061.

11. Burchak, O.N.; Mugherli, L.; Ostuni, M.; Lacapere, J.J.; Balakirev, M.Y. Combinatorial Discovery of Fluorescent Pharmacophores by Multicomponent Reactions in Droplet Arrays. J. Am. Chem. Soc. 2011, 133, 10058-10061, doi:10.1021/ja204016e.

12. Kumawat, L.K.; Kumar, M.; Bhatt, P.; Sharma, A.; Asif, M.; Gupta, V.K. An easily accessible optical chemosensor for $\mathrm{Cu}^{2+}$ based on novel imidazoazine framework, its performance characteristics and potential applications. Sens. Actuators B 2017, 240, 365-375, doi:10.1016/j.snb.2016.08.184.

13. Pericherla, K.; Kaswan, P.; Pandey, K.; Kumar, A. Recent Developments in the Synthesis of Imidazo[1,2-a] pyridines. Synthesis 2015, 47, 887-912, doi:10.1055/s-0034-1380182.

14. Bagdi, A.K.; Santra, S.; Monir, K.; Hajra, A. Synthesis of imidazo[1,2-a] pyridines: A decade update. Chem. Commun. 2015, 51, 1555-1575, doi:10.1039/c4cc08495k. 
15. Groebke, K.; Weber, L.; Mehlin, F. Synthesis of Imidazo[1,2-a] annulated Pyridines, Pyrazines and Pyrimidines by a Novel Three-Component Condensation. Synlett 1998, 6, 661-663, doi:10.1055/s-1998-1721

16. Blackburn, C.; Guan, B.; Fleming, P.; Shiosaki, K.; Tsai, S. Parallel Synthesis of 3-Aminoimidazo[1,2-a] pyridines and pyrazines by a New Three-Component Condensation. Tetrahedron Lett. 1998, 39, 3635-3638, doi:10.1016/S0040-4039(98)00653-4.

17. Bienaymé, H.; Bouzid, K. A New Heterocyclic Multicomponent Reaction for the Combinatorial Synthesis of Fused 3-Aminoimidazole. Angew. Chem. 1998, 110, 2349-2352, doi:10.1002/(SICI)15213773(19980904)37:16.

18. Chernyak, N.; Gevorgyan, V. General and Efficient Copper-Catalyzed Three-Component Coupling Reaction towards Imidazoheterocycles: One-Pot Synthesis of Alpidem and Zolpidem. Angew. Chem. Int. Ed. 2010, 49, 2743-2746, doi:10.1002/anie.200907291.

19. Mishra, S.; Ghosh, R.; Mechanistic studies on a new catalyst system (CuI-NaHSO $\left.4 \times \mathrm{SiO}_{2}\right)$ leading to the one-pot synthesis of imidazo [1,2-a] pyridines from reactions of 2-aminopyridines. Synthesis 2011, 34633470, doi:10.1055/s-0030-1260255.

20. Reddy, B.V.S.; Reddy. P. S.; Reddy, Y.J.; Yadav, J.S. InBr3-catalyzed three-component, one-pot synthesis of imidazo [1,2-a] pyridines. Tetrahedron Lett. 2011, 52, 5789-5793, doi:10.1016/j.tetlet.2011.08.110.

21. Ebrahim, K.; Mohammad, G.; Mehri, N.N.; Reza, F. Novel One-Pot Three Component Reaction for the Synthesis of [2-(Alkylsulfanyl)imidazo[1,2-a]pyridin-3-yl](aryl)methanone. J. Comb. Chem. 2010, 12, 41-44, doi:10.1021/cc900103r.

22. Devi, N.; Rawal, R.K.; Singh, V. Diversity-oriented synthesis of fused-imidazole derivatives via GroebkeeBlackburne-Bienayme reaction: Tetrahedron 2015, 71, 183-232, doi:10.1016/j.tet.2014.10.032;

23. Shaaban, S.; Abdel-Wahab, B.F. Groebke-Blackburn-Bienaymé multicomponent reaction: Emerging chemistry for drug discovery. Mol. Divers. 2016, 20, 233-254, doi:10.1007/s11030-015-9602-6.

24. Kurva, M.; Pharande, S.G.; Quezada-Soto, A.; Gámez-Montaño. R. Ultrasound assisted green synthesis of bound type bis-heterocyclic carbazolyl imidazo[1,2-a] pyridines via Groebke-Blackburn-Bienayme reaction. Tetrahedron Lett. 2018, 59, 1596-1599, doi:10.1016/j.tetlet.2018.03.031.

25. Claudio-Catalan, M.A.; Pharande, S.G.; Quezada-Soto, A.; Kishore, K.G.; Renteria-Gomez, A.; Padilla-Vaca, F.; Gamez-Montano, R. Solvent-and Catalyst-Free One-Pot Green Bound-Type Fused Bis-Heterocycles Synthesis via Groebke-Blackburn-Bienayme Reaction/SNAr/Ring-Chain Azido-Tautomerization Strategy. ACS Omega 2018, 3, 5177-5186, doi:10.1021/acsomega.8b00170.

26. Unnamatla, M.V.B.; Islas-Jácome, A.; Quezada-Soto, A.; Ramírez-López, S.C.; Flores-Álamo, M.; GámezMontaño, R. Multicomponent One-Pot Synthesis of 3-Tetrazolyl and 3-Imidazo[1,2-a]pyridin Tetrazolo[1,5a]quinoline. J. Org. Chem. 2016, 81, 10576-10583, doi:10.1021/acs.joc.6b01576.

(C) 2018 by the authors. Licensee MDPI, Basel, Switzerland. This article is an open access article distributed under the terms and conditions of the Creative Commons Attribution (CC BY) license (http://creativecommons.org/licenses/by/4.0/). 